\section{ladies dental talk jetzt auch für Führungsfrauen aus Zahntechnik}

Die Zahnmedizin wird weiblich. Doch wie sieht es mit der Zahntechnik aus? Noch sind hier nur wenige Frauen auf Entscheidungsebene präsent. Dr. Karin Uphoff, Initiatorin des ladies dental talk, möchte dies ändern. Wie? Indem sie Führungsfrauen aus Dentallaboren sichtbar macht und sie untereinander sowie mit den Zahnärztinnen vernetzt. „Wir Frauen können gut von- und miteinander lernen. Diese Möglichkeit möchte ich nun auch verstärkt den Zahntechnikerinnen bieten.“ Nach 6 Jahren ladies dental talk-Erfahrung baut Uphoff für sie deshalb einen eigenen Bereich auf. Der ladies dental talk startete als Netzwerkformat für Zahnärztinnen, die querdenken und die Zukunft mitgestalten möchten. Anfangs belächelt oder skeptisch beäugt, ist er inzwischen aufgrund seiner besonderen Veranstaltungskonzepte branchenweit beachtet und anerkannt. Speziell für Führungsfrauen der Zahntechnik wird es nun regelmäßig Treffen geben mit hochkarätigen Inhalten und viel Zeit

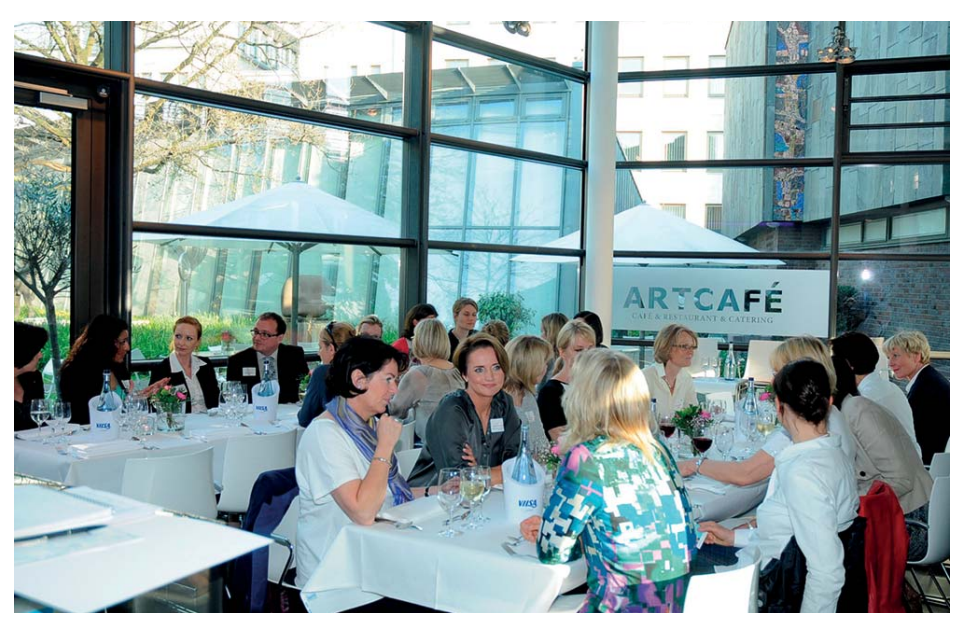
GmbH, Marburg
Raum zum Netzwerken. Geleitet werden sie von der ladies dental talk-Gründerin. Den Anfang macht das Stärkungs-Seminar „Vom Vertrauen zum Vertrag: mit gutem Gefühl authentisch verkaufen" am 3. und 4. Juni im Kurparkhotel Bad Wilhelmshöhe in Kassel-Wilhelmshöhe mit der zertifizierten Unternehmensberaterin und Janus-Trainerin Claudia Mog.

Nach einer Pressemitteilung des ladies dental talk c/o uphoff pr \& marketing 